\title{
ENTREVISTA COM LEILA MEZAN ALGRANTI
}

Entrevista realizada em janeiro de 2020 com a Historiadora e Professora de História da Unicamp-SP, Dra. Leila Mezan Algranti, via e-mail. Foram entrevistadores os historiadores e professores de História da UFPA, Dr. José Maia Bezerra Neto e Dra. Sidiana da Consolação Ferreira de Macêdo.

\section{INTRODUÇÃO À ENTREVISTA:}

A Profa. Dra. Leila Mezan Algranti está entre as grandes e talentosas historiadoras brasileiras da atualidade. Graduada em História pela USP, lá também fez Mestrado e Doutorado, orientada pelo Historiador e Professor de História Dr. Fernando Novais, tornando-se professora universitária na UnicampSP. Autora de livros consagrados na historiografia brasileira ( $O$ Feitor Ausente; Honradas e Devotas: mulheres da Colônia; Atos de censura, livros de devoção - ensaios de história da leitura e dos livros na América portuguesa), Leila Algranti tem se destacado nos últimos anos pelos estudos e trabalhos no campo da História da Alimentação, sendo uma das percursoras na historiografia brasileira dessa temática. Sobre a sua trajetória e formação acadêmica, livros e obviamente pesquisas sobre a História da Alimentação, fizemos essa entrevista, que bem vale uma aula pela riqueza do que é dito e ensinado, agradecendo à Professora Leila Algranti a gentiliza de dispor de seu tempo para responder nossas questões.

1- Sidiana: Professora nos fale um pouco sobre sua formação acadêmica. Graduação? Mestrado? Doutorado?

Leila Mezan Algranti - Costumo dizer que sou historiadora por formação e vocação, pois o trabalho tanto nos arquivos, como na sala de aula me encanta e absorve totalmente. Ingressei no curso de Graduação em História, na USP, no início dos anos 1970, um período muito difícil para as universidades brasileiras devido à censura à liberdade de pensamento e de expressão. Mas havia aulas incríveis, professores dedicadíssimos e criativos que incentivavam a turma a estudar e a pesquisar. Como consequência -- assim como eu -- vários colegas ingressaram no curso de Mestrado e, posteriormente, no Doutorado, tornando-se professores universitários e seguindo a carreira acadêmica. Eu realizei o Mestrado e o Doutorado em História na USP, orientada por Fernando Novais, a quem devo minha formação e a paixão pelo ofício. Além de me ensinar a pensar historicamente, Novais me transmitiu um sentimento forte de que "fazer" História é muito interessante, pode ser divertido, mas é algo difícil: é para profissionais, como ele insiste até hoje.

2- José Maia: Sobre seu percurso de Pesquisa você fez no mestrado um importante trabalho sobre escravidão urbana (livro Feitor Ausente), no doutorado fez o estudo sobre mulheres reclusas (livro 
Honradas e Devotas) e depois nos últimos anos vem se dedicando com maestria à investigação sobre a História da Alimentação então, como você escolheu seus temas, particularmente da História da Alimentação? Como foi esse encontro com a História da Alimentação?

Leila Mezan Algranti - Como nos ensinou Marc Bloch, ao estudar o passado, os historiadores não podem voltar as costas para o presente. Ao contrário, este se manifesta naquilo que interrogam ao passado e, claro, na forma como respondem às perguntas. Comigo não foi diferente. Os temas que escolhi aprofundar foram motivados pelas circunstâncias do mundo à minha volta e, certamente, pelos movimentos da historiografia brasileira.

Meu envolvimento com a história colonial, por exemplo, se deu em grande parte, devido ao interesse pelo tema da escravidão africana, o qual promovia grandes polêmicas na historiografia brasileira nos anos 1970. Acreditava-se que a compreensão do chamado "modo de produção escravista" explicaria melhor nossa sociedade e o estágio de desenvolvimento do capitalismo no qual o Brasil se encontrava. Estudar a escravidão africana e seus desdobramentos era uma maneira de procurar entender não só a vida econômica e social brasileiras -- profundamente marcadas por essa instituição -- como captar a essência da colonização portuguesa na América. Acho que foi por tudo isso que ingressei no Mestrado com um projeto de pesquisa sobre a escravidão africana no Rio de Janeiro.

Por outro lado, como muitos historiadores da minha geração, meu principal interesse era escrever a história dos "excluídos", me aproximar de agentes históricos anônimos, cidadãos comuns, e tentar "ouvi-los". Interessava-me (e ainda me interessa) reconstruir as práticas sociais e culturais no mundo colonial. Por diversos caminhos e com o auxílio de diferentes temas, minha grande questão tem sido: como viviam e o que pensavam, em determinadas situações históricas, os homens e as mulheres na América portuguesa? Em meados dos anos 1980, a então recente "história das mulheres" era um grande estímulo para se tentar desconstruir as imagens que predominavam sobre as mulheres coloniais: reclusas, omissas, pouco importantes e subjugadas a pais e maridos opressores. Me encantei com este desafio e entrei nos arquivos com tal objetivo. O resultado desse trabalho foi o livro Honradas e Devotas: mulheres da Colonia. Mas quando conclui o Doutorado, a Historia Social começava a mudar de direção. Seus novos ventos me levaram à história cultural que estimulava os historiadores a desvendarem o mundo dos livros, das leituras e dos leitores. Atos de censura, livros de devoção - ensaios de história da leitura e dos livros na América portuguesa é o titulo do livro que reúne um conjunto de estudos que apresentei no Concurso para Livre-docente na Unicamp, cujas mulheres reclusas foram, mais uma vez, as grandes protagonistas.

Costumo brincar dizendo que abandonei definitivamente o ambiente das clausuras femininas da Colônia saindo pela porta da cozinha. Não antes, porém, de investigar o que se passava nesse 


\section{Entrevista:}

\section{Leila Mezan Algranti}

\section{José Maia BEZERRA NETO; Sidiana da Consolação Ferreira de MACEDO}

espaço de produção, consumo e sociabilidades em torno da comida. Da cozinha dos conventos à cozinha das casas grandes é o titulo do meu primeiro projeto de pesquisa dedicado à história da alimentação na América portuguesa, no início dos anos 2000.

As profundas transformações nos hábitos alimentares que impactaram a vida doméstica e profissional dos indivíduos ao longo do século $\mathrm{XX}$, aliadas ao meu interesse e experiência em pesquisar sobre a vida privada na Colônia podem estar na origem do meu encontro com a História da Alimentação. Desde que escrevi o capitulo intitulado "Família e Vida doméstica" (1997) para a Coleção História da Vida Privada, minha relação com a temática só cresceu, assim como sua importância na historiografia nacional e internacional. Além disso, o tema da alimentação tornou-se polêmico, inquietante e dominante na imprensa, na televisão e demais mídias. Como eu disse anteriormente, tudo parte do que está acontecendo à nossa volta. As ideias são sociais.

\section{3- Sidiana: Qual a importância do tema da História da Alimentação?}

Leila Mezan Algranti - Podemos dizer que o tema da Alimentação chegou tardiamente aos domínios da História, comparado ao lugar que ocupou nas outras Ciências Humanas. Na Antropologia, por exemplo, encontra-se associado a essa disciplina desde o seu surgimento, no século XIX. Por outro lado, aprendemos com os sociólogos que a alimentação tem uma função estruturante na sociedade, quer se trate de atividades de produção, de distribuição ou de consumo de alimentos. O que nos leva a indagar: e no campo da História o que acontece? A alimentação é objeto de estudo da História? A resposta é certamente positiva, uma vez que a alimentação oferece uma chave essencial para descrever e explicar a vida cotidiana de uma comunidade. Afinal, encontra-se presente em todos os aspectos da vida social, estendendo-se da sobrevivência física à religiosidade dos indivíduos, passando pelas esferas da política e do poder, da sexualidade e das diferenças de gênero, como destacaram Martin Bruegel e Bruno Laurioux. Porém, foi apenas nos anos 1960, com o desenvolvimento da historiografia dos Annales, que a alimentação passou a entrar na pauta dos historiadores de forma mais contundente e não apenas como um objeto complementar de estudos, fato que acontecia até então. Os trabalhos de Fernand Braudel e Jean louis Flandrin foram altamente inspiradores e, paulatinamente, o tema e seus múltiplos objetos foram conquistando os interesses dos historiadores. Com o avançar das pesquisas na Europa, a historiografia brasileira também se voltou para a temática, a fim de mostrar que alimentação é bem mais do que comida. Trata-se de um conjunto de práticas que envolvem desde a produção até o consumo dos alimentos, as quais são portadoras de significados simbólicos. Ou seja, constituiu-se na História um campo novo e muito vasto de investigação, o qual ocupa hoje importante espaço na agenda dos historiadores. 


\section{Entrevista:}

\section{Leila Mezan Algranti}

\section{José Maia BEZERRA NETO; Sidiana da Consolação Ferreira de MACEDO}

\section{4- Sidiana: Como você vê hoje o estudo da história da Alimentação no Brasil?}

Leila Mezan Algranti - O campo de estudo da História da Alimentação no Brasil está hoje em pleno desenvolvimento e eu diria que talvez estejamos vivendo um de seus momentos mais frutíferos dos últimos anos. Isto porque a área se expandiu largamente e teve uma boa acolhida por parte dos jovens historiadores que passaram a dedicar suas pesquisas acadêmicas a temáticas próprias desta área de estudos. Grande parte da produção histórica no Brasil se dá, há mais de 30 anos, no interior dos Programas de Pós Graduação. Este é também o espaço das renovações metodológicas e de abordagens, o que contribui para o surgimento de novos temas, entre os quais, eu destaco aqueles referentes às práticas alimentares no país, independentemente do período histórico. Lembro-me que em 2004 participei de uma mesa redonda no encontro Regional da ANPUH - São Paulo, intitulada $O$ Lugar da Alimentação na História. Buscávamos naquele momento defender e estimular a pesquisa e a escrita de uma história da alimentação no Brasil. Mais de 15 anos depois, teses e dissertações se sucederam nos Programas de Pós Graduação sobre temas voltados à história da alimentação no Brasil. Também surgiram dossiês em revistas especializadas dedicados ao tema, assim como grupos de pesquisa e encontros científicos que estimularam o debate acadêmico e as especializações na área. Nossos pesquisadores têm atuado em redes internacionais de investigação, divulgando os resultados de seus estudos fora do país e usufruindo dos benefícios da era virtual para estreitarem os intercâmbios acadêmicos. A historiografia sobre alimentação no Brasil, hoje, não é apenas mais uma tendência historiográfica. Está totalmente consolidada e em expansão.

5- José Maia: Recentemente você organizou uma coletânea de História da Alimentação em conjunto com a Professora Sidiana Ferreira em vias de publicação. Porque você achou importante a organização dessa obra à luz da historiografia?

Leila Mezan Algranti - Sim, História e Alimentação - Brasil séculos XVI- XXI está prestes a vir a público. É uma obra que repensa certas ideias e conceitos há muito enraizados no pensamento brasileiro sobre o comer no nosso país. Esperamos que possa ser um livro para ensino e debate nas salas de aula, uma vez que os principais estudos de caráter geral e mais abrangente sobre a temática datam dos anos 1960. Nossa proposta principal em organizar esse livro foi oferecer um balanço dos resultados recentes da pesquisa na área de História da Alimentação, a fim de divulgar as amplas possibilidades de abordagem, fontes e temáticas deste campo de estudos em expansão na historiografia brasileira. Alem disso, a publicação de uma obra coletiva desse porte (29 capítulos, 32 autores e mais de 600 páginas) deverá proporcionar maior visibilidade aos grupos de estudo e pesquisa aos quais os autores do livro encontram-se vinculados. A ideia é também promover o reconhecimento dos Programas de Pós Graduação envolvidos com a História da Alimentação no 


\section{Entrevista:}

\section{Leila Mezan Algranti}

Brasil. Certamente tivemos que fazer escolhas relativas a temas, localidades e recortes cronológicos. Foi um trabalho envolvente e intenso reunir todos esses elementos e pessoas. Agora, que o livro está praticamente pronto, tenho certeza de que Sidiana Macedo compartilha comigo a sensação de que valeu muito a pena a empreitada. Quem sabe não nos envolvemos no segundo volume?

6- Sidiana: Que conselhos você daria aos jovens historiadores?

Leila Mezan Algranti - Penso que os desafios para um jovem historiador hoje são diferentes daqueles que se colocaram para a minha geração. Tudo se transforma ao longo do tempo. O acesso às plataformas de documentos e de bibliografia na era da história digital provocou o fenômeno da "história sem fim", pois se as fontes são ilimitadas, a pergunta é: quando devemos encerrar a etapa de consulta às fontes e começar a analisar os dados coletados? De fato, essa pergunta sempre assombrou os historiadores. Porém, se a coleta é mais fácil e abundante hoje, a análise dos dados pode ser mais difícil, advindos de fontes mais fragmentadas e de difícil coesão. Assim, o que procuro colocar para meus alunos é não buscarem a verdade dos fatos históricos e lembrarem-se sempre de que os documentos, assim como as interpretações, também são fabricados, como nos alertou Fernando Bouza. Dessa forma, talvez eles possam evitar os anacronismos, lição que aprendi com meu mestre e orientador.

7- José Maia: Agora, uma última pergunta: se você não fosse historiadora, que profissão gostaria de ter?

Leila Mezan Algranti - Sinceramente não sei. Nessa altura da minha vida profissional acho muito difícil conjugar o verbo no tempo condicional. Só consigo dizer que certamente faria algo vinculado às Ciências Humanas. Possivelmente cursaria História depois de qualquer outro curso...

Texto recebido em: 30/03/2020

Texto aprovado em: 01/05/2020 